\title{
The use of internal audits as a tool to analyze skills and competences
}

Fernández, J' ${ }^{\mathrm{a}}$; Cruells, M. ${ }^{a}$; Escaja, N. ${ }^{\mathrm{a}}$; Garrido, J.A. ${ }^{\mathrm{a}}$; Giménez, J. ${ }^{\text {; }}$ ' Llauradó, M. ${ }^{\mathrm{a}}$; Roca, A. ${ }^{\text {; }}$ Rodríguez, L. ${ }^{a}$; Sagristà, M.Ll. ${ }^{a}$; Navarro, C. ${ }^{a}$; Bernad, J.O. ${ }^{\text {a }}$ and Barcelona, $\mathbf{P} .^{\mathbf{a}}$

${ }^{a}$ Quality Committee, Faculty of Chemistry. Universitat de Barcelona. C/ Martí i Franquès, 1. 08028 Barcelona. Spain.

\section{Abstract}

The degrees of the faculty of Chemistry of the University of Barcelona have implemented a quality management system (QMS) (Real Decreto 1393/2007; Real Decreto 861/2010). One of the common subjects taught in formative period of the students is Quality and Prevention. The competences that the students must acquire are knowing the QMS and the basis of certification and accreditation. They must also have skills to plan and propose actions to ensure quality and to prepare documentation of a quality management system, among others. The aim of the work is the execution of internal audits carried out by students to analyze the degree of skills and competences obtained by the auditors throughout the course Quality and Prevention.

Keywords: Audit; skill; competences, laboratories. 


\section{Introduction}

The degrees of the faculty of Chemistry of the University of Barcelona have implemented a quality management system (QMS) (Real Decreto 1393/2007 and Real Decreto 861/2010). One of the common subjects taught in formative period of the students is Quality and Prevention. The competences that the students must acquire are knowing the QMS and the basis of certification and accreditation (Companyó and Rios, 2002). They must also have skills to plan and propose actions to ensure quality and to prepare documentation of a quality management system, among others.

The audit may be a useful tool not only for the acquisition of skills and abilities but also for evaluating the students. The training for developing the capabilities of auditors can include experimental programs. Auditing is a structured process that involves the application of analytical skills but during the audit they should also receive guidance on the professional approach to ethics, fundamental principles and the consequences of unethical behavior.

The audit process involves the understanding of the entity to be audited, the internal processes and the related controls, to perform analytical procedures and to report the conclusions. According to the standard ISO 19011 (ISO 19011), they have to verify the observance of effective controls.

\section{Methodology}

The methodology is based on three basic pillars: training students, conducting audits and monitoring and evaluating the process (Fernandez et al., 2015). First a training session is carried out with the students auditors where they receive the basic features of the audit and information about the tasks, together with the relevant documentation. This documentation includes the audit questionnaire, the manual of auditors, audit procedures and form audit report. The audit questionnaire will help auditors to identify potential interviewers and to make sure that auditors and observers are familiar with all relevant procedures.

For his performance as auditors, students are supervised by a member of a teaching innovation group (TIG) which developes, at the same time, the double duty of training and observing the work of students.

After the audit, the students prepared a report that it is evaluated by teachers of the subject of Quality and Prevention. A representative sample of these reports is then revised by members of TIG. The students must be able to draw conclusions about their work and the laboratories audited. Finally, through a series of surveys (Companyó et al., 2008) of students working as auditors, audited students and teachers, it is assessed the level of satisfaction with the work done. 
A total of 102 students have been selected, over the two academic years in which this project has been developed. After a brief training, these students have acted as auditors in 49 audits, Table 1, involving the participation of 99 students and 49 teachers as partners in laboratories audited. During the audit, the students were able to work with generic skills and ethics, speaking and writing ability, the ability to dialogue, leadership, analysis and interpretation of data, management quality, respectful labor the environment, safety, etc.

Table 1. Audits conducted during the years 2013-14 and 2014-15

\begin{tabular}{ccc}
\hline Variable & $\mathbf{2 0 1 3 / 2 0 1 4}$ & $\mathbf{2 0 1 4 / 2 0 1 5}$ \\
\hline Number of students auditors & 44 & 58 \\
Number of students audited & 40 & 59 \\
Number of teachers involved & 20 & 29 \\
Number of audits & 20 & 29 \\
Number of laboratories audited & 18 & 20 \\
Number of surveys about auditors & 18 & 27 \\
Number of surveys to audited students & 40 & 60 \\
Number of teachers surveyed & 18 & 28 \\
\hline
\end{tabular}

It was established that each audit process was conducted by two students, several groups of two students were therefore formed. Audits were carried out in laboratories during the scheduled morning and afternoon laboratory sessions. Prior to the audit, with the advice of a member of the TIG, the audit was also planned with the teachers of the involved laboratories.

During the audit, students were supervised by a teacher of the subject, who, as previously mentioned, developed a dual task of training and observation of the work carried out by students during the audit.

The students prepared the final report which included the following sections: i) general data of the audited laboratories, ii) results of the observations with regard to the system of quality management, environment and security, strengths and weaknesses of the system, nonconformities and iii) establishment opportunities for improvement.

Finally a number of surveys adressed to all participants of the audit were conducted to analyze, by means of specific questions, all the aspects related to the preparation and implementation of the audit. 


\section{Results and Discussion}

Auditing is a process that involves the use of analytical skills and judgement fulfilling technical standards. To adquire the required skills, the auditors must have prior knowledge and experience training. The skills that the students of the Quality and Prevention include to plan and propose actions to ensure quality according to the different management systems and to develop documentation of a quality management system. They must take the culture of quality and risk prevention and be aware of the need of the organization and work planning.

Audits can improve the scientific and technical competences of students, focusing on basic and applied aspects for a scientist or engineer, respectively, and also skills related to work as a team as the students have to interact with their corresponding partner in the audit.

The results of the audits are related to:

- All documentation related indicators.

- The improvement in the generic skills of students.

- The introduction of the students in the knowledge of quality management systems.

- Identifying any deficiencies in experimental subjects related to both the laboratories and the organizational aspects and, therefore, having a better understanding of the functioning of laboratories and to propose practical measures to their improvement.

The achievement of skills can be done through the training sessions and corresponding personal interaction when developing audits.

Students are not only limited to indicate the response that they consider most appropriate, according to the audit questionnare, in accordance with the responses of the partners, but point to a series of observations (objective evidence) that are valuable for the implementation of the report. These evidences are valuables for a futher analysis of the audited laboratory.

The survey of students, who have participated as auditors, about the degree of satisfaction with the new learning mode is shown in Figure 1. They have to answer 18 questions, 4 questions are concerning aspects before the audit, 8 questions about the audit process and the last 6 ones concerning the end results of the audit. Some example of the questions are:

4.- The available documentation helped you to prepare the audit?

8.- Was easy communication with teachers? 
Fernández, J; Cruells, M.; Escaja, N.; Garrido, J.A.; Giménez, J.; Llauradó, M.; Roca, A.; Rodríguez, L.; Sagristà, M.Ll.; Navarro, C.; Bernad, J.O.; Barcelona, P.

13.- How easy was preparing the report?

In general, the satisfaction of the students involved in the audit is quite good, with an average value just below 4, for both years. Question 11 and 13 are related to lidership in the audit and the ease in preparing the report.

Better results are found when analyzing the survey of the audited teachers, Figure 2. The questions with lower qualification, 2 and 8 , are related with the statement of the objectives of the audit and the request for evidence to corroborate assertions. Some examples of the questions are:

3.- Was communication fluid?

5.- The questions were understood?

10.- Did auditors show enough knowledge?

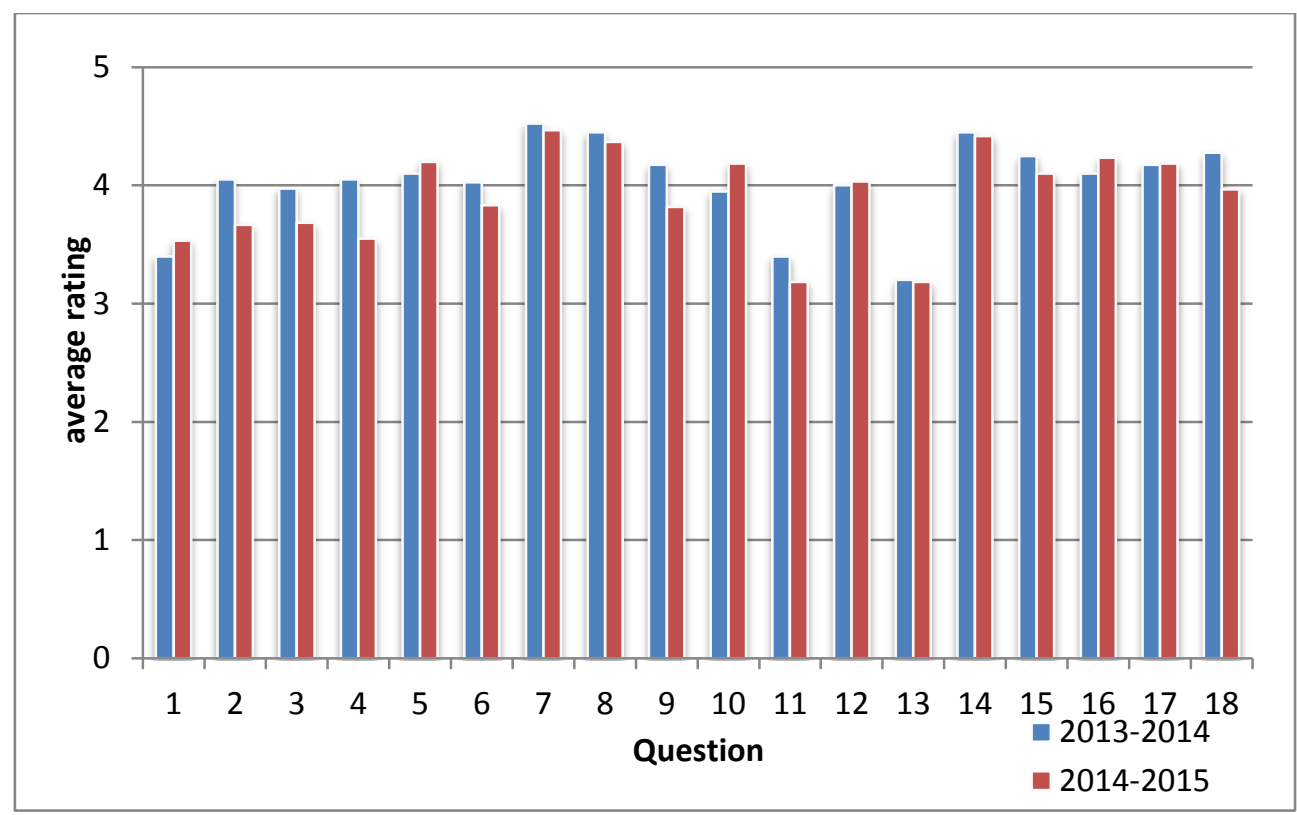

Figure 1.Satisfaction survey of auditors.

From the analysis of reports of the audit, it can be stated that students have improved the skills related to the analysis and interpretation of data, the ability of oral and written expression, the capacity for dialogue and leadership and the ability to find and integrate new knowledge and attitudes. Furthermore, the reports show that they have been able to integrate the dynamics of management systems of quality, safety and environment training. 
Students have shown understanding of the work of others adapting and understanding different situations always with a critical look at an established system.

Importantly, the reports submitted by students have the rigor and quality enough to constitute a useful tool for the assessment and implementation of corrective actions in the teaching laboratories of the Faculty of Chemistry, allowing continuous improvement practice and performance of laboratories teaching.

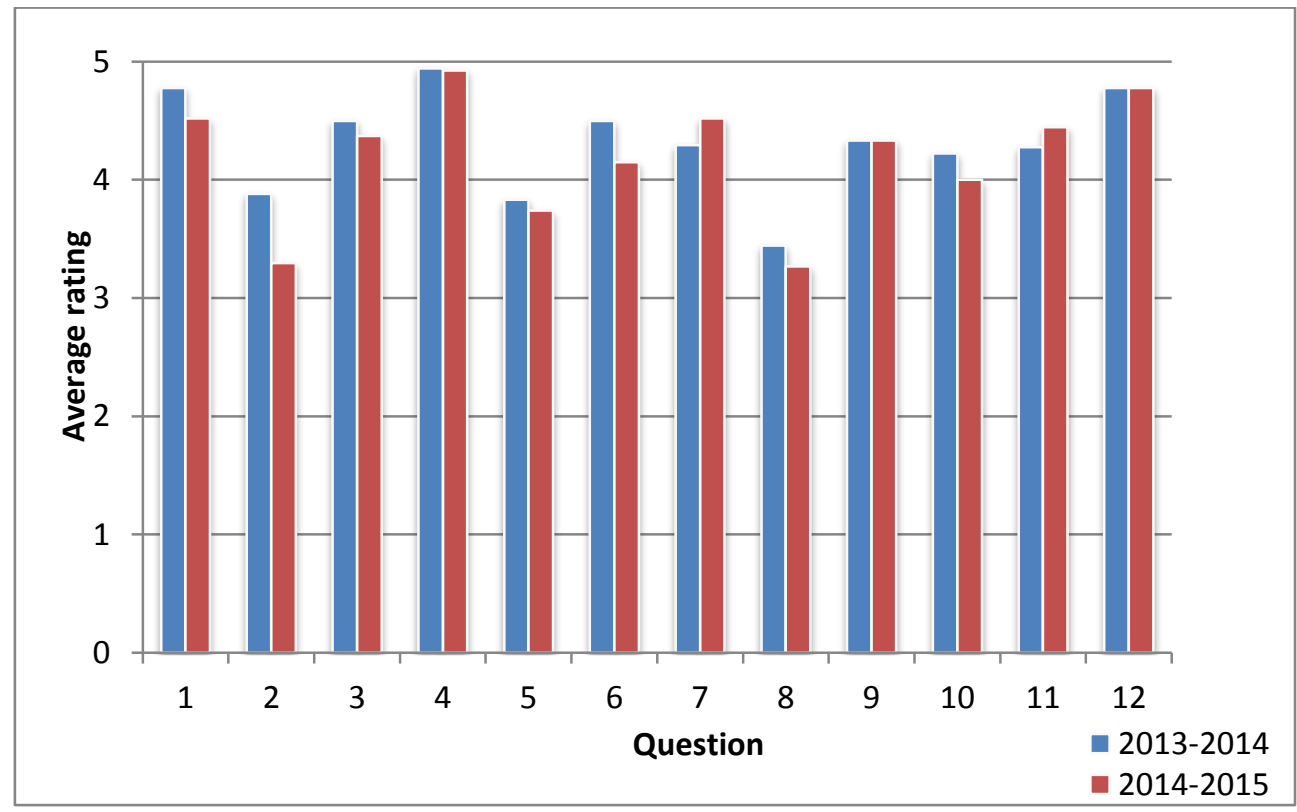

Figure 2.Satisfaction survey of audited teachers.

Conducting audits has forced the direct interaction between the auditor (student) and the auditee (teacher and trainee) which enables working capacity of understanding and communication of the work done by others.Surveys have shown a good level of involvement among people involved in audits and allowed to evaluate the usefulness of the same for students in their acquisition of skills.

At the same time, analysis of the results has led to a precise knowledge of the state of the laboratories of the Faculty of Chemistry.

\section{References}

Companyó,R., Rios, A. (2002). Garantía de la Calidad en los laboratorios analíticos. Madrid: Síntesis. 
Fernández, J; Cruells, M.; Escaja, N.; Garrido, J.A.; Giménez, J.; Llauradó, M.; Roca, A.; Rodríguez, L.; Sagristà, M.Ll.; Navarro, C.; Bernad, J.O.; Barcelona, P.

Companyó, R. Cruells, M, Garrido,J.A., Giménez, J, Granell, J., Llauradó, M, Mallol, J., Navarro, C., Pérez, I, Sainz, D., Urpí, F., Vallés, A, Bernad, O., Paredes, A. (2008). Las encuestas a las empresas: una fuente de información en el desarrollo de competencias de los estudiantes El cambio en la cultura docente universitaria - Contenidos de las congerencias y comunicaciones del V CIDUI, electronic format. ISBN 978-84-8458286-1. Lleida

Fernández, J., Companyó, R., Cruells, M., Escaja, N, Garrido, J.A., Giménez, J., Llauradó, M., Roca, A., Rodríguez, L., Sagristà, M.L1., Navarro, C., Vallés, M.A. Bernad, J.O., Escobar, C. (2015). Competency training of students of the Faculty of Chemistry of the University of Barcelona by conducting internal audits. Procedia - Social and Behavioral Sciences, 196, 59-62 (2015).

ISO 19011 (2011) Guidelines for auditing management systems.

Real Decreto 1393/2007, de 29 de octubre, por el que se establece la ordenación de las enseñanzas universitarias.

Real Decreto 861/2010, de 2 de Julio, por el que se modifica el Real Decreto 1393/2007. 